\title{
Prevalence of people at risk of developing type 2 diabetes mellitus and the involvement of community pharmacies in a national screening campaign: a pioneer action in Brazil
}

\author{
Cassyano J. Correr ${ }^{1}$, Wendel Coura-Vital ${ }^{2^{*}}\left(\mathbb{0}\right.$, Josélia C. Q. P. Frade ${ }^{3}$, Renata C. R. M. Nascimento ${ }^{2}$, \\ Lúbia G. Nascimento ${ }^{2}$, Eliete B. Pinheiro ${ }^{3}$, Wesley M. Ferreira ${ }^{3}$, Janice S. Reis ${ }^{4}$, Karla F. S. Melo ${ }^{5}$, \\ Roberto Pontarolo ${ }^{1}$, Mônica S. A. Lenzi ${ }^{3}$, José V. Almeida ${ }^{3}$, Hermelinda C. Pedrosa ${ }^{6,7}$ and Walter S. J. João ${ }^{3}$
}

\begin{abstract}
Background: Brazil is one of top 10 countries with the highest number of people with diabetes mellitus (DM), affecting 16.8 million peoples. It is estimated that 7.7 million people (20-79years) in the country have not yet been diagnosed, representing an under-diagnosis rate of $46.0 \%$. Herein we aimed to screen people for high blood glucose or risk for developing type 2 DM (T2DM) through community pharmacies in Brazil.
\end{abstract}

Methods: A cross-sectional study was carried out in November 2018, involving 977 pharmacists from 345 municipalities in Brazil. The study evaluated people between 20 and 79 years old without a previous diagnosis of DM. Glycemia was considered high when its value was $\geq 100 \mathrm{mg} / \mathrm{dL}$ fasting and $\geq 140 \mathrm{mg} / \mathrm{dL}$ in a casual feeding state. The FINDRISC (Finnish Diabetes Risk Score) was used to estimate the risk for developing T2DM. The prevalence of high blood glucose was estimated and the associated factors were obtained using Poisson's multivariate analysis with robust variance.

Results: During the national screening campaign, 17,580 people were tested with the majority of the consultations (78.2\%) being carried out in private pharmacies. The population was composed mainly of women (59.5\%) and people aged between 20 and 45 years (47.9\%). The frequency of participants with high blood glucose was 18.4\% (95\% Cl 17.9-19.0). Considering the FINDRISC, $22.7 \%$ of people had a high or very high risk for T2DM. The risk factors associated with high blood glucose were: Body Mass Index $>25 \mathrm{~kg} / \mathrm{m}^{2}$, abdominal circumference $>94 \mathrm{~cm}$ for men and $>80 \mathrm{~cm}$ for women; education level below 15 years of study, no daily intake of vegetables and fruits; previous diagnosis of arterial hypertension; history of high blood glucose and family history of DM.

Conclusions: This is the largest screening study that evaluated the frequency of high blood glucose and its associated factors in a population without a previous diagnosis ever performed in community pharmacies in Brazil. These results may help to improve public health policies and reinforce the role of pharmacists in screening and education actions aimed at this undiagnosed population in a continent-size country such as Brazil.

\footnotetext{
*Correspondence: wendelcoura@ufop.edu.br

${ }^{2}$ Programa de Pós Graduação em Ciências Farmacêuticas, Escola de

Farmácia, Universidade Federal de Ouro Preto, Ouro Preto, Minas Gerais, Brazil

Full list of author information is available at the end of the article
}

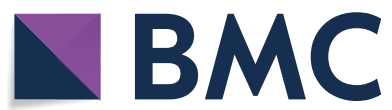
adaptation, distribution and reproduction in any medium or format, as long as you give appropriate credit to the original author(s) and the source, provide a link to the Creative Commons licence, and indicate if changes were made. The images or other third party material in this article are included in the article's Creative Commons licence, unless indicated otherwise in a credit line to the material. If material is not included in the article's Creative Commons licence and your intended use is not permitted by statutory regulation or exceeds the permitted use, you will need to obtain permission directly from the copyright holder. To view a copy of this licence, visit http://creativeco mmons.org/licenses/by/4.0/. The Creative Commons Public Domain Dedication waiver (http://creativecommons.org/publicdomain/ zero/1.0/) applies to the data made available in this article, unless otherwise stated in a credit line to the data. 
Keywords: Diabetes mellitus, Risk factors, Chronic disease, Prevalence

\section{Background}

The epidemiological transition is a major challenge for health systems and societies in the Americas [1]. Population aging, urbanization, and changes in lifestyle have impacted the prevalence of chronic noncommunicable diseases (NCD), with emphasis on hypertension, diabetes mellitus, and dyslipidemia $[1,2]$.

Brazil is one of the top 10 countries in the world with the highest number of people with DM and currently is the 5th in the ranking [3]. International estimates indicate a growing trend in the prevalence of DM in the country, with an expected increase ranging from 6 to $7.8 \%$ in 2030 [4]. Despite the lack of nationwide studies on the prevalence of DM, results from the Vigitel 2017 household survey showed a prevalence of $7.7 \%$ in the 27 Brazilian capitals, with $7.1 \%$ for men and $8.1 \%$ for women [5]. The 2019 9th IDF Diabetes Atlas estimated that in in the Brazilian population between 20 and 79 years old there are approximately 16.8 million people with diabetes in Brazil, and 7.7 million undiagnosed DM, representing an under-diagnosis proportion of 46.0\% [3].

Several studies have pointed out impressive data on pre-diabetes in Brazil. The National Health Survey, conducted from 2014-2015, which used glycated hemoglobin (HbA1c) as a diagnostic tool in a sample over 8,500 people, identified a prevalence of pre-diabetes ranging from $6.8 \%$ to $16.9 \%$, depending on the criteria used [6]. The ELSA longitudinal study, involving Brazilian adults, reported pre-diabetes prevalence ranging from $20-59 \%$ of the sample recruited among university professional staff [7]. In addition to the diagnostic challenges, control rates of DM in Brazil remain unsatisfactory. The last largest nationwide study analyzing glucose control was conducted in 2006 and showed that $75 \%$ of 6.671 individuals with T2DM and $90 \%$ of those with type 1 DM (T1DM) assisted in private and public services by either specialists or no-specialists presented HbA1c higher than 7\% [8]. Other studies have shown similar or even worse results among T1DM $[9,10]$.

In Brazil, the treatment of diabetes micro and macrovascular complications represents the main component of the disease expenses, with $48.2 \%$ of the cost attributed to medicines to treat these complications $[11,12]$. Therefore, early diagnosis of T2DM is important to prevent chronic complications associated with the disease and to reduce the costs associated with health care delivery.

The Finnish Diabetes Risk Score (FINDRISC) is a simple, non-invasive and easy-to-use screening instrument used to predict the risk of an adult developing DM2 in
10 years [13]. This instrument has been adopted worldwide to lead T2DM prevention programs in primary health care [14-17] and has been adapted by the Brazilian Diabetes Society to be applied during national awareness campaigns in Brazil [18]. Studies conducted in several countries have shown that pharmacies are successful partners in programs for screening and diagnosing diabetes and in the identification of risk factors for cardiovascular diseases [19-23]. In Brazil, pharmacies are establishments that provide pharmaceutical services as well as individual and collective health guidance, including assessment of capillary blood glucose, blood pressure measurement, among other procedures. Pharmacists are higher education health professionals with responsibilities for carrying out clinical activities, including screening, education, and monitoring of patients [24, 25]. In this context, the present study aimed to identify, among people without a previous diagnosis of DM, the frequency of high blood glucose in the Brazilian population and the associated factors.

\section{Methods}

\section{Study design and population}

A cross-sectional study was carried out in November 2018, involving 977 pharmacists from 345 municipalities in Brazil, to assess the frequency of high blood glucose in individuals without a previous diagnosis of DM.

Brazil is the largest country in South America, with a territorial area of $8,510,820.623 \mathrm{Km}^{2}$, divided into five geographic regions (North, South, Midwest, Southeast, and Northeast) and subdivided into 27 federative units, including the Federal District. The estimated national population, for the year 2018, was $210,867,954$ inhabitants [26]. To calculate the ideal sample size, there were considered the Brazilian population aged between 20 and 79 years (141,802,185 people; IBGE 2017); an estimated prevalence of pre-diabetes or DM of 23\% [27]; 95\% confidence level; and 1\% estimate accuracy. The estimated sample for the country $(11,750)$ was further stratified taking into account the population aged 20 to 79 years in each federative unit.

People aged between 20 and 79 years old who were attended at any of the selected pharmacies, during the study period, were invited by pharmacists to participate in the study. Participants could be in their feeding routine (unknown diet) or fasting ( $8 \mathrm{~h}$ without any caloric intake). The exclusion criteria were: participants' records presenting blood glucose data collected with glucometers without ISO 15197: 2013 certification (ISO, 2013); previous 
diagnosis of DM; any data collected with non-standard anthropometric tape; age $<20$ years or $>79$ years; lack of data on weight (measured on a scale), height, Body Mass Index (BMI) and or abdominal circumference (AC); capillary blood glucose (CBG) lower than $70 \mathrm{mg} / \mathrm{dL}$ without confirmation or CBG higher than $300 \mathrm{mg} / \mathrm{dL}$ without confirmation.

\section{Selection of pharmacies and training of pharmacists}

Participated in the study volunteer pharmacists from community pharmacies (private and public), located in different municipalities throughout the national territory. Community pharmacy is a type of health care facility that provides pharmaceutical services or with a given mission around medicines [24, 28]. Pharmacies were selected in a non-probabilistic manner, by fulfilling the following criteria: (i) ability to collect and send data by electronic means; (ii) agreeing to use their inputs (glucometer, blood glucose test strips, scale, anthropometric tape, office supplies); (iii) be located in a municipality that has a public primary health care service and that was covered by the Mobile Emergency Care Service; (iv) be regularly enrolled in the Regional Pharmacy Council of their jurisdiction, with full-time pharmaceutical coverage; (v) have a patient care room allowing visual and sound privacy (pharmaceutical care room).

The recruitment of the the study population was carried out by broadcasting media campaigns (television, radio, Federal Pharmacy Board website [29], and a website developed exclusively for the campaign [30]) and locally, by the participating pharmacies. Standardized disclosure materials were provided to participating pharmacies.

\section{Testing protocol and data collection}

During November 2018, people who attended any of the selected pharmacies were invited by the pharmacist to participate in the study, being informed about the objectives of the project and the inclusion criteria. Those who agreed to participate signed the Free and Informed Consent Form, answered a questionnaire with personal information, clinical data and the FINDRISC [13], translated and cross-culturally adapted to Brazilian Portuguese [31]. The FINDRISC analyses eight clinical characteristics: age, BMI, AC, daily physical activity, eating habits, blood pressure, use of antihypertensive medication, history of hyperglycemia, and family history of diabetes. The final score corresponds to the sum of the scores attributed to each question, ranging from 0 to 26 , and the individual risk of developing T2DM was stratified into five categories, ranging from low to very high risk [15]. Subsequently, anthropometric measurements and CBG test were performed. Height was obtained with a tape measure fixed on the wall. Weight was obtained by a digital or analog scale registered by the National Health Surveillance Agency (Anvisa), available at the time of the evaluation. BMI was obtained by dividing the weight (in kilograms) by the square of height (in meters); AC was measured using a professional anthropometric tape, following the recommendations of the Brazilian Association for the Study of Obesity and Metabolic Syndrome [32]; CBG tests were performed using glucometers registered by Anvisa, with ISO 15,197: 2013 (ISO, 2013) certification, such as Accu Check Performa ${ }^{\circledR}$ (Roche), Accu Check Performa Connect ${ }^{\circledR}$ (Roche), Accu Check Guide ${ }^{\circledR}$ (Roche), One Touch Select Plus Flex ${ }^{\circledR}$ (J\&J), Contour Plus ${ }^{\circledR}$ (Bayer), G-Tech Free Lite (GTech), Freestyle Freedom Lite ${ }^{\circledR}$ (Abbott), and Freestyle Optium Neo ${ }^{\circledR}$ (Abbott). The results were interpreted according to the recommendations of the Brazilian Diabetes Society, considering the patient's feeding status at the time of the CBG test [18]. CBG levels less than $100 \mathrm{mg} / \mathrm{dL}$ were considered normal when fasting or less than $140 \mathrm{mg} /$ $\mathrm{dL}$, in a casual feeding state.

The interpretation of the CBG result and the subsequent orientation to the participant were performed by the pharmacist. Participants with results suggestive of pre-diabetes or DM were referred to the local public or private health system, with a proper filled in declaration form [25], containing the result of the parameters evaluated during the screening procedures.

\section{Data analysis}

After filling in the survey instruments, the data were entered into an online platform (Surveymonkey) and later exported for analysis using the Stata Version 14.0 software.

A difference observed in the degrees of risk defined by FINDRISC and CBG levels were evaluated by chisquare test.

The Poisson multivariate model, with robust variance, was used to identify the risk factors associated with high blood glucose and the estimates were obtained using the prevalence ratio (PR) with 95\% CI. Initially, a univariate analysis was performed and the variables that showed a statistical association in this analysis $(p<0.25)$ were analyzed in a multivariate model. Variables with more than two categories were transformed into dummy variables. For the construction of the final model, a complete model was started, containing all the variables, and the successive disposal of the variables was carried out until only those with significance level remained in the model $(p<0.05)$. 


\section{Results}

The final sample screened was 20,171 participants, of which 17,580 (87.2\%) were eligible for the study (Fig. 1).

\section{Characteristics of the assessed population}

Of the 17,580 participants included, most were women $(59.5 \%)$ and the predominant age group was less than 45 years old (47.9\%). The mean and median age were $46 \pm 15.7$ years, with the first and third quartiles being 33 and 59, respectively. The predominant skin color was white (47.3\%), followed by brown (38.0\%). In terms of education, $77.7 \%$ of the participants had more than 8 years of study, $18.0 \%$ reported 8 to 10 years of study, $29.1 \%$ indicated 11 to 14 years, and $30.6 \%$ informed 15 or more years of study. Regarding the practice of physical

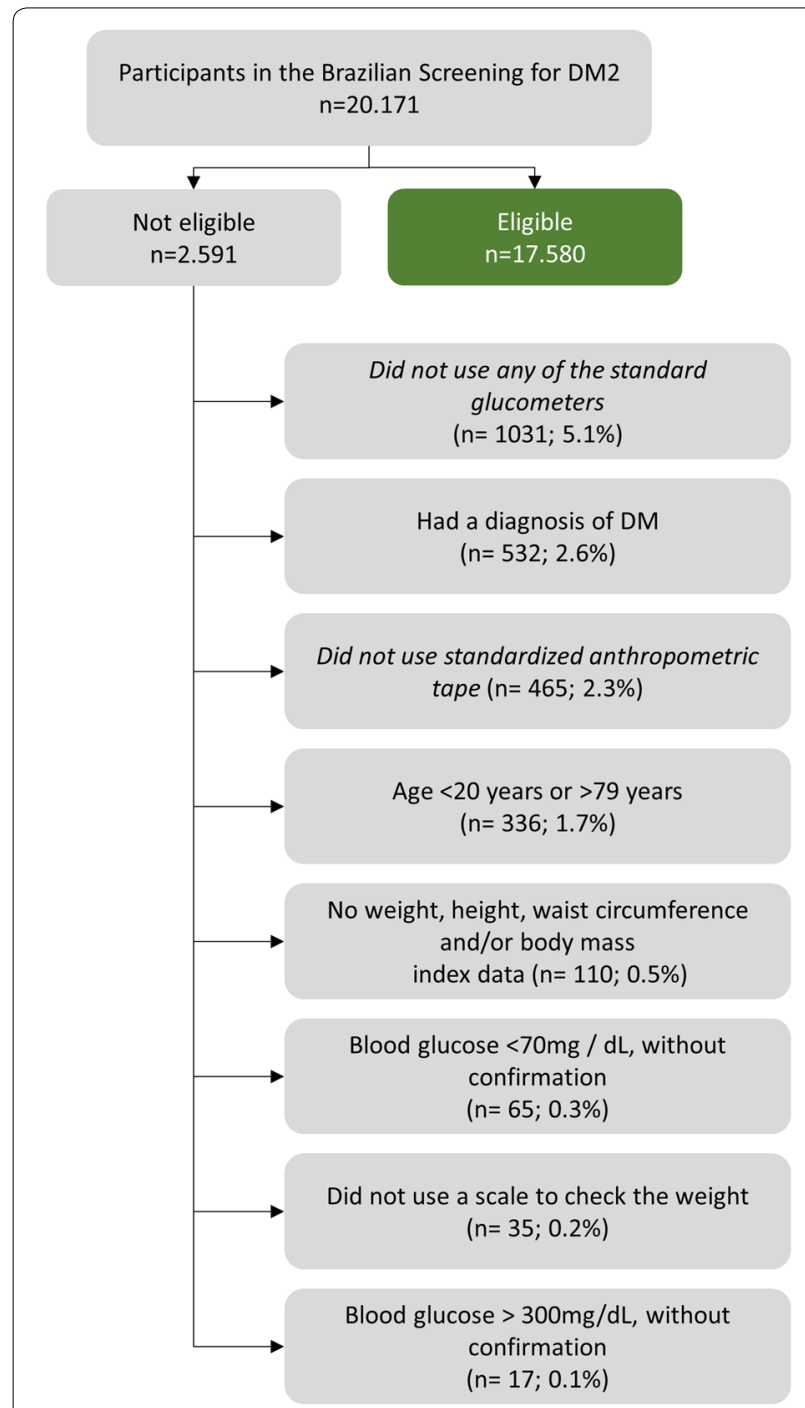

Fig. 1 Population included in the screening of high blood glucose in Brazil, 2018 activities, $68.3 \%$ reported not practicing any activity and, concerning eating habits, $43.0 \%$ did not eat vegetables or fruits daily. It was observed that $30.8 \%$ of the sampled population self-reported hypertension or used antihypertensive medication. As for blood glucose rates, 15.8\% reported having high glucose levels events in the past and $58 \%$ informed a family history of T1DM or T2DM (Table 1).

\section{Risk of developing DM2 in the next 10 years}

According to the FINDRISC, $22.1 \%(\mathrm{n}=3873)$ were at low risk for developing T2DM ( 1 in 100 develops the disease); $35.1 \%(\mathrm{n}=6169)$ slightly moderate risk ( 1 in 25 develops the disease); $20.1 \%(\mathrm{n}=3523)$ moderate risk (1 in 6 develops the disease); $19.6 \%(n=3436)$ high risk ( 1 in 3 develops the disease) and $3.1 \%(n=555)$ very high risk (1 in 2 develops the disease) (Table 2).

Among the participants with low or moderate risk, 24.9 and $36.8 \%$, respectively, had normal CBG. Participants who presented high or very high FINDRISC were mainly those who had high CBG levels, with percentages much higher than those found in individuals with normal CBG, corresponding to 33.5 and $8.0 \%$ respectively.

\section{Frequency of high capillary blood glucose levels}

The frequency of high CBG levels (fasting CBG $\geq 100 \mathrm{mg}$ / $\mathrm{dL}$ or in random condition $\geq 140 \mathrm{mg} / \mathrm{dL}$ ) among the individuals enrolled in this present screening was $18.4 \%$ (95\% CI 17.9-19.0). When the frequency by geographic region was assessed, the Midwest presented the highest frequency (24.6\%; 95\% CI: $22.4-27.0$ ), followed by the North (22.5\%; 95\% CI 20.4-24.8) and Northeast (19.8\%; 95\% CI: $18.8-20.8$ ) regions (Fig. 2).

\section{Risk factors for high capillary blood glucose}

Preliminary selection of variables $(p<0.25)$, through univariate analysis, is described in Table 3 . According to multivariate analysis (Table 4), the BMI of $25-30 \mathrm{~kg} /$ $\mathrm{m}^{2}$ (PR 1.1) and BMI $>30 \mathrm{~kg} / \mathrm{m}^{2}$ (PR 1.3), when compared with $\mathrm{BMI}<25 \mathrm{~kg} / \mathrm{m}^{2}$; AC for men of $94-102 \mathrm{~cm}$ or for women of $80-88 \mathrm{~cm}$ (PR 1.2) as well as AC for men $>102 \mathrm{~cm}$ or for women $>88 \mathrm{~cm}$ (PR 1.3) compared to $\mathrm{AC}<94 \mathrm{~cm}$ for men or $<80 \mathrm{~cm}$ for women, increased the risk of high CBG. People with less education had a higher frequency of high CBG, compared to people with 15 or more years of education (illiterate PR 1.5). People who did not eat fruits or vegetables every day (PR 1.1), reported being hypertensive or use medicines for high blood pressure (PR 1.1), and those informing a high glycemia rate in the past (PR 1.9) and having first-degree relatives with either T1DM or T2DM (PR 1.3) were associated with a higher prevalence of high CBG. The PR 
Table 1 Baseline characteristics of the population included in the screening of high blood glucose in Brazil, 2018

\begin{tabular}{|c|c|c|}
\hline Variables & $\mathrm{n}$ & $\%$ \\
\hline \multicolumn{3}{|l|}{ Gender } \\
\hline Male & 7112 & 40.5 \\
\hline Female & 10,468 & 59.5 \\
\hline \multicolumn{3}{|l|}{ Age (years) } \\
\hline $20-45$ & 8412 & 47.9 \\
\hline $45-54$ & 3374 & 19.2 \\
\hline $55-64$ & 3188 & 18.1 \\
\hline $65-79$ & 2606 & 14.8 \\
\hline \multicolumn{3}{|l|}{ Abdominal circumference $(\mathrm{cm})$} \\
\hline Male $<94$ & 2916 & 41.0 \\
\hline $94-102$ & 2099 & 29.5 \\
\hline$>102$ & 2097 & 29.5 \\
\hline Female $<80$ & 2222 & 21.2 \\
\hline $80-88$ & 2184 & 20.9 \\
\hline$>88$ & 6062 & 57.9 \\
\hline \multicolumn{3}{|l|}{ Color } \\
\hline White & 8318 & 47.3 \\
\hline Brown & 6679 & 38.0 \\
\hline Black & 2253 & 12.8 \\
\hline Yellow & 192 & 1.1 \\
\hline Indigenous & 52 & 0.3 \\
\hline Uninformed & 86 & 0.5 \\
\hline \multicolumn{3}{|l|}{ Educational level (years) } \\
\hline Illiterate & 814 & 4.6 \\
\hline $1-3$ & 173 & 1.0 \\
\hline $4-7$ & 2936 & 16.7 \\
\hline $8-10$ & 3166 & 18.0 \\
\hline $11-14$ & 5108 & 29.1 \\
\hline$\geq 15$ & 5383 & 30.6 \\
\hline \multicolumn{3}{|l|}{ Practice of physical activity } \\
\hline Yes & 5575 & 31.7 \\
\hline No & 12,005 & 68.3 \\
\hline \multicolumn{3}{|l|}{ Consumption of vegetables and/or fruits } \\
\hline Every day & 10,024 & 57.0 \\
\hline Do not eat every day & 7556 & 43.0 \\
\hline \multicolumn{3}{|c|}{ Diagnosis or use of medicines for hypertension } \\
\hline Yes & 5413 & 30.8 \\
\hline No & 12,167 & 69.2 \\
\hline \multicolumn{3}{|l|}{ High blood glucose in the past } \\
\hline Yes & 2780 & 15.8 \\
\hline No & 14,800 & 84.2 \\
\hline \multicolumn{3}{|c|}{ Family member with type 1 or 2 diabetes mellitus } \\
\hline No & 7377 & 42.0 \\
\hline Yes (grandparents, uncles, cousins) & 3741 & 21.3 \\
\hline Yes: parents. siblings or children & 6462 & 36.7 \\
\hline
\end{tabular}

Table 2 Risk for developing T2DM (FINDRISC), according to capillary blood glucose levels, regardless of dietary status, Brazil, 2018

\begin{tabular}{llcc}
\hline \multirow{2}{*}{ FINDRISC } & \multicolumn{2}{l}{ Blood glucose $(\mathbf{m g} / \mathbf{d L})^{*}$} & \multirow{2}{*}{ Total $\mathbf{n}$ (\%) } \\
\cline { 2 - 3 } & Normal $\mathbf{n}(\%)$ & High $\mathbf{n}(\%)$ & \\
\hline Low risk & $3565(24.9)$ & $308(9.5)$ & $3873(22.1)$ \\
Slightly moderate risk & $5275(36.8)$ & $894(27.6)$ & $6169(35.1)$ \\
Moderate risk & $2828(19.8)$ & $695(21.4)$ & $3523(20.1)$ \\
High risk & $2350(16.4)$ & $1086(33.5)$ & $3436(19.6)$ \\
Higher risk & $297(2.1)$ & $258(8.0)$ & $555(3.1)$ \\
\hline
\end{tabular}

*Glycemia considered normal: fasting $<100 \mathrm{mg} / \mathrm{dL}$ or casual $<140 \mathrm{mg} / \mathrm{dL}$. Results excluding 24 patients with blood glucose results $<70 \mathrm{mg} / \mathrm{dL}$

values obtained in the multivariate model were adjusted for the participants' age and sex.

\section{Discussion}

This is the largest study ever conducted in pharmacies in all regions of Brazil that assessed the frequency of high blood glucose levels and the risk of developing diabetes. Performing NCD screening is important because it can identify asymptomatic people at high risk or with initial signs and symptoms of a disease, allowing for timely diagnosis and treatment, which is very important for a disease such as diabetes. According to the WHO, a substantial fraction of the disease burden and mortality due to NCD are related to a small set of risk factors, among which stand out smoking, inadequate food consumption, physical inactivity, and excessive consumption of alcoholic beverages [33]. Early detection of people at risk of developing T2DM is very important, since changes in lifestyle, including physical activity and proper diet, can reduce the incidence of the disease by approximately $58 \%$ $[14,18]$. In addition, its early detection and intervention in patients with T2DM can minimize complications from other comorbidities such as non-alcoholic fatty liver disease, with insulin resistance being a common pathophysiological mechanism that mutually interferes in the progression of both diseases [34, 35].

It was found that the frequency of high CBG levels was higher in the Midwest, North, and Northeast regions. These findings can be explained by the heterogeneous profile of the Brazilian population, related to lifestyle and prevalence of obesity which has been increasing. In Brazil, overweight $\left(B M I>25 \mathrm{~kg} / \mathrm{m}^{2}\right)$ and obesity rates are spreading in all age groups, both sexes, and all income levels, with the obesity rates being more frequent in the population with lower family income [36]. Indeed, according to data from Vigitel 2018 [37], the prevalence of obesity $\left(\mathrm{BMI}>30 \mathrm{~kg} / \mathrm{m}^{2}\right)$ in adults is $19.8 \%$, with the highest frequencies observed in capitals of the Midwest, 


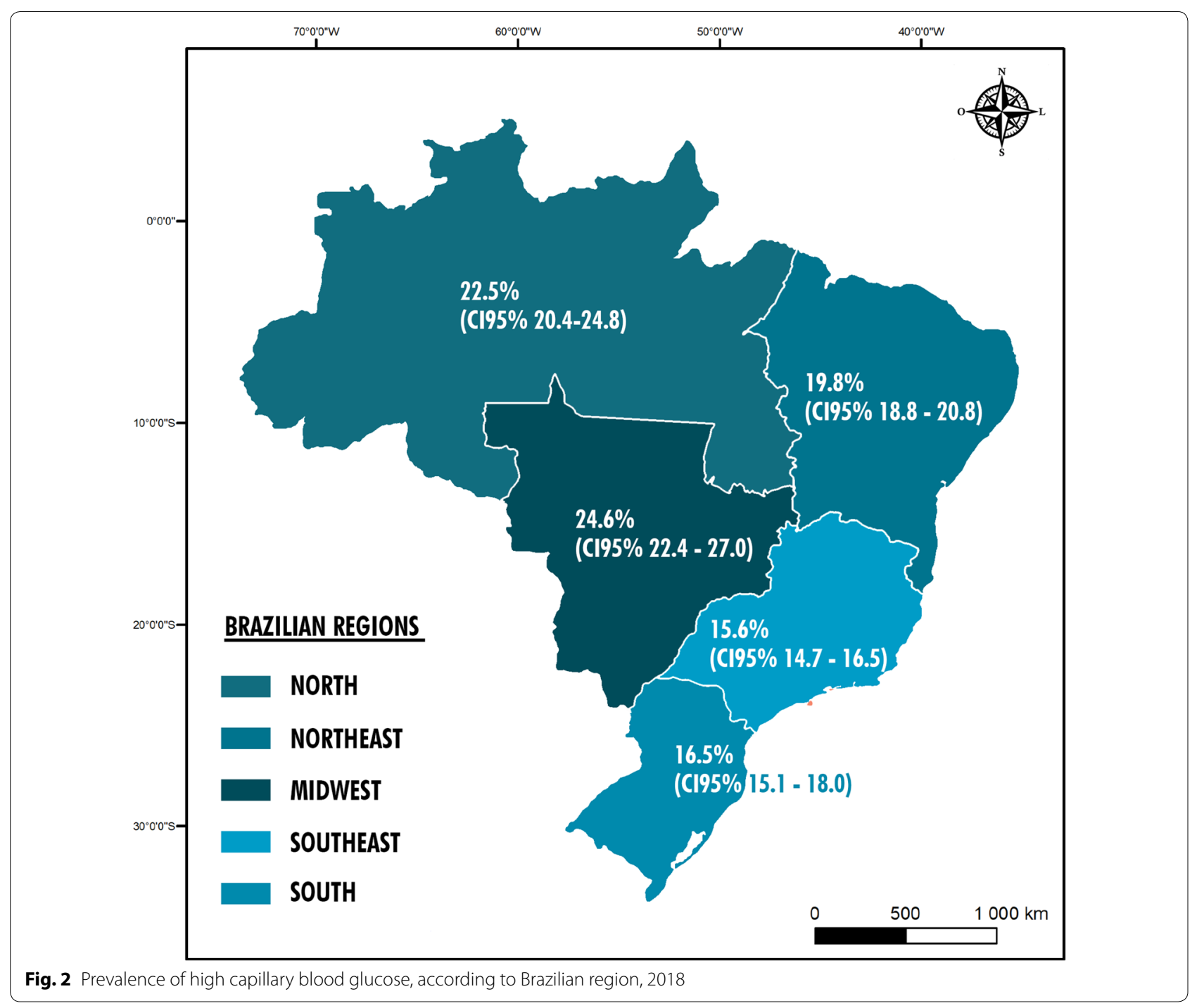

North, and Northeast regions, with emphasis on the capital cities like Cuiabá (23.0\% CI 95\% 20.5-25.4), Manaus (23.0\% CI 95\% 19.7-26.3), and Recife (21.9\% CI 95\% 19.3-24.4).

Regarding the consumption of fruits and vegetables, a similar distribution was found, with the lowest percentages observed in the North and Northeast regions [37]. The Vigitel survey also pointed out that consumption of fruits and vegetables is more frequent among women and, despite the increase in the consumption of these foods observed in the last 10 years, only $23.1 \%$ of Brazilians consume the 5 daily portions at least 5 times a week, as recommended by the WHO [37]. Generally, diets have a high sugar intake, acting as the main source of advanced glycation endproducts (AGEs). These compounds are toxic and are associated with the pathogenesis of diet-related diseases, such as diabetes, insulin resistance, among others [38]. The AGEs, due to hyperglycemia and insulin resistance present in people with diabetes, are an extra source of reactive oxygen species (ROS) which overload the cellular antioxidant machinery, leading the cell to a state of oxidative stress [39]. Thus, natural compounds with antioxidant properties, such as citrus fruits, tomatoes, green tea, can prevent the harmful effects of AGEs, providing benefits in the control of T2DM.[38, 40]. In turn, ROS mediate chronic inflammatory processes that are directly related to the micro and macrovascular complications of diabetes, which are diabetic retinopathy, neuropathy and nephropathy [41, 42]. Inflammatory processes can also be triggered by diets with low intake of vitamin $\mathrm{D}$, a fact corroborated by study that show an inverse correlation between blood levels of vitamin D and C-reactive protein. This relationship being more pronounced in patients with inflammatory 
Table 3 Univariate analysis of population characteristics associated with high blood glucose levels, Brazil, 2018

\begin{tabular}{|c|c|c|c|c|}
\hline \multirow[t]{2}{*}{ Variables } & \multicolumn{2}{|c|}{ Blood glucose (mg/dL)* } & \multirow[t]{2}{*}{ PR (Cl95\%) } & \multirow[t]{2}{*}{$p$ value } \\
\hline & Normal (n/\%) & High (n/\%) & & \\
\hline \multicolumn{5}{|l|}{ Gender } \\
\hline Male & $8720(60.9)$ & $1734(53.5)$ & & \\
\hline Female & $5595(39.1)$ & $1507(46.5)$ & $1.3(1.2-1.4)$ & 0.01 \\
\hline \multicolumn{5}{|l|}{ Age (years) } \\
\hline $20-45$ & $7486(52.3)$ & $913(29.2)$ & & \\
\hline $45-54$ & 2655 (18.5) & $716(22.1)$ & $1.9(1.8-2.1)$ & 0.01 \\
\hline $55-64$ & $2357(16.5)$ & $827(25.5)$ & $2.4(2.2-2.6)$ & 0.01 \\
\hline $65-79$ & $1817(12.7)$ & $785(24.2)$ & $2.8(2.6-3.0)$ & 0.01 \\
\hline \multicolumn{5}{|l|}{ Body mass index } \\
\hline$<25$ & $5220(35.5)$ & $782(24.1)$ & & \\
\hline $25-30$ & $5595(39.1)$ & $1326(40.9)$ & $1.5(1.4-1.6)$ & 0.01 \\
\hline$>30$ & $3500(24.5)$ & $1133(35.0)$ & $1.9(1.7-2.0)$ & 0.01 \\
\hline \multicolumn{5}{|l|}{ Abdominal circumference $(\mathrm{cm})$} \\
\hline$₫<94$ or $q<80$ & $4491(31.4)$ & 635 (19.6) & & \\
\hline đ94-102 or $980-88$ & $3518(24.6)$ & $760(23.4)$ & $1.4(1.3-1.6)$ & 0.01 \\
\hline$\sigma^{t}>102$ or $q>88$ & $6306(44.0)$ & $1846(57.0)$ & $1.8(1.7-2.0)$ & 0.01 \\
\hline \multicolumn{5}{|l|}{ Color } \\
\hline White & $6821(47.6)$ & $1489(45.9)$ & & \\
\hline Brown & $5471(38.2)$ & $1200(37.0)$ & $1.0(0.9-1.1)$ & 0.91 \\
\hline Black & $156(1.1)$ & $36(1.1)$ & $1.0(0.8-1.4)$ & 0.77 \\
\hline Yellow & $1754(12.3)$ & $491(15.2)$ & $1.2(1.1-1.3)$ & 0.01 \\
\hline Indigenous & $44(0.3)$ & $8(0.3)$ & $0.8(0.4-1.6)$ & 0.64 \\
\hline Uninformed & $69(0.5)$ & $17(0.5)$ & $1.1(0.7-1.7)$ & 0.65 \\
\hline \multicolumn{5}{|l|}{ Educational level (years) } \\
\hline$\geq 15$ & $4644(32.4)$ & $734(22.7)$ & & \\
\hline $11-14$ & $4347(30.4)$ & $752(23.2)$ & $1.1(1.0-1.2)$ & 0.10 \\
\hline $8-10$ & $2498(17.4)$ & $665(20.5)$ & $1.5(1.4-1.7)$ & 0.01 \\
\hline $4-7$ & $2143(15.0)$ & $791(24.4)$ & $2.3(2.1-2.6)$ & 0.01 \\
\hline $1-3$ & $123(0.9)$ & $49(1.5)$ & $2.5(1.8-3.5)$ & 0.01 \\
\hline Illiterate & $560(3.9)$ & $250(7.7)$ & $2.8(2.4-3.3)$ & 0.01 \\
\hline \multicolumn{5}{|l|}{ Practice of physical activity } \\
\hline Yes & $4608(32.2)$ & $964(29.7)$ & & \\
\hline No & 9707 (67.8) & $2277(70.3)$ & $1.1(1.0-1.2)$ & 0.01 \\
\hline \multicolumn{5}{|c|}{ Consumption of vegetables and/or fruits } \\
\hline Every day & $8216(57.4)$ & $1796(55.4)$ & & \\
\hline Do not eat every day & 6099 (42.6) & $1445(44.6)$ & $1.1(1.0-1.1)$ & 0.04 \\
\hline \multicolumn{5}{|c|}{ Diagnosis or use of medicines for hypertension } \\
\hline No & $10,362(72.4)$ & $1787(55.1)$ & & \\
\hline Yes & $3953(27.6)$ & $1454(44.9)$ & $1.8(1.7-1.9)$ & 0.01 \\
\hline \multicolumn{5}{|l|}{ High blood glucose in the past } \\
\hline No & $12,533(87.5)$ & $2243(69.2)$ & & \\
\hline Yes & $1782(12.5)$ & $998(30.8)$ & $2.4(2.2-2.5)$ & 0.01 \\
\hline \multicolumn{5}{|c|}{ Family member with type 1 or 2 diabetes mellitus } \\
\hline No & $6159(43.0)$ & $1204(37.1)$ & & \\
\hline Yes (grandparents, uncles, cousins) & $3228(22.5)$ & $505(15.6)$ & $0.8(0.7-0.9)$ & 0.01 \\
\hline Yes: (parents, siblings or children) & $4928(34.4)$ & $1532(47.3)$ & $1.4(1.3-1.5)$ & 0.01 \\
\hline
\end{tabular}

*Glycemia considered normal. fasting $<100 \mathrm{mg} / \mathrm{dL}$ or casual $<140 \mathrm{mg} / \mathrm{dL}$. Results excluding 24 patients with blood glucose results $<70 \mathrm{mg} / \mathrm{dL}$. $\delta^{\star}-$ Male; $\$$-Female 
Table 4 Multivariate analysis of characteristics associated with high blood glucose, Brazil, 2018

\begin{tabular}{|c|c|c|}
\hline Variables & PR (Cl95\%) crude & PR (Cl95\%) ajusted* \\
\hline \multicolumn{3}{|l|}{ Body mass index } \\
\hline$<25$ & - & - \\
\hline $25-30$ & $1.5(1.4-1.6)$ & $1.1(1.1-1.2)$ \\
\hline$>30$ & $1.9(1.7-2.0)$ & $1.3(1.2-1.4)$ \\
\hline \multicolumn{3}{|l|}{ Abdominal circumference $(\mathrm{cm})$} \\
\hline o $<94$ or $q<80$ & - & - \\
\hline ò 94-102 or o 80-88 & $1.4(1.3-1.6)$ & $1.2(1.1-1.3)$ \\
\hline ot $>102$ or $q>88$ & $1.8(1.7-2.0)$ & $1.3(1.2-1.5)$ \\
\hline \multicolumn{3}{|l|}{ Educational level (years) } \\
\hline$\geq 15$ & - & - \\
\hline $8-10$ & $1.5(1.4-1.7)$ & $1.3(1.1-1.4)$ \\
\hline $4-7$ & $2.3(2.1-2.6)$ & $1.4(1.3-1.5)$ \\
\hline $1-3$ & $2.5(1.8-3.5)$ & $1.5(1.2-1.9)$ \\
\hline Illiterate & $2.8(2.4-3.3)$ & $1.5(1.3-1.7)$ \\
\hline \multicolumn{3}{|c|}{ Consumption of vegetables and/or fruits } \\
\hline Every day & - & - \\
\hline Do not eat every day & $1.1(1.0-1.1)$ & $1.1(1.1-1.2)$ \\
\hline \multicolumn{3}{|c|}{ Diagnosis or use of medicines for hypertension } \\
\hline No & - & - \\
\hline Yes & $1.8(1.7-1.9)$ & $1.1(1.1-1.2)$ \\
\hline \multicolumn{3}{|l|}{ High blood glucose in the past } \\
\hline \multicolumn{3}{|l|}{ No } \\
\hline es & $2.4(2.2-2.5)$ & $1.9(1.8-2.0)$ \\
\hline \multicolumn{3}{|c|}{ Family member with type 1 or 2 diabetes mellitus } \\
\hline No & - & - \\
\hline Y es (parents, siblings or children) & $1.4(1.3-1.5)$ & $1.3(1.2-1.4)$ \\
\hline
\end{tabular}

đ-Male; + -Female. *Final model adjusted for age and sex

diseases, such as diabetes, compared to patients with non-inflammatory diseases [43]. In addition, it has been speculated that vitamin D supplementation may contribute to reducing the risk of developing diabetes in patients at risk of developing the disease [44].

Similar to the results reported by Passos et al. (2005), it was verified a positive relationship between physical inactivity and high CBG [45]. Sedentary lifestyle has been associated with insulin resistance in individuals without a diagnosis of diabetes, regardless of obesity [46, 47]. Reporting of previous arterial hypertension was also associated with high CBG. It is known that hypertension has a prevalence up to three times higher in people with DM when compared to those who do not have the disease, being the major determinant of atherosclerotic cardiovascular diseases (ASCVD) in this population $[48,49]$.

The percentage of people at high and very high risk of developing T2DM in Brazil was similar to the screening performed in pharmacies in Spain (23.5\% had a high risk of diabetes -FINDRISC $>14$ points) [50] and smaller than the risk reported by the screening performed in Thailand, in seven pharmacies, which showed a prevalence of $48 \%$ of high risk for DM [51]. The frequency of high CBG in Brazil was higher than the prevalence found in other countries such as Spain, Switzerland, and Thailand [5052], indicating the need for multidisciplinary monitoring of these people.

T2DM is characterized by a long asymptomatic period before the diagnosis [14]. The early diagnosis of T2DM contributes to the reduction of ASCVD, prevention of microvascular complications (retinopathy, neuropathy, kidney disease), and premature mortality [14, 47, 53, 54]. People with T2DM have a two to four times greater risk of developing coronary heart disease, when compared to the general population, and approximately $8 \%$ of people with pre-diabetes develop retinopathy [47]. Moreover, more recent data have shown high percentages of peripheral neuropathy among people with obesity and preDM (29\% versus $11 \%$ with normal glucose), and ranges from 11 to $34 \%$ among individuals with pre-DM [55]. Thus, early interventions to prevent or delay progression to T2DM represent an important benefit not only 
for increasing life expectancy and quality of life, but also reducing costs related to the management of the disease and its complications [15].

Success in the treatment of DM depends on the concomitant implementation of three categories of interventions: educational, self-monitoring, and pharmacological strategies. Whenever possible, it is recommended that care for people with diabetes should include a health care professional (HCP) interdisciplinary team composed of professionals with the proper qualification and practical experience in health education activities [56]. Pharmacists working in community pharmacies can contribute not only with HCP screening and education, but also with the monitoring of patients with DM, in collaboration with other HCP thus helping to improve the treatment and disease control.

A systematic review and meta-analysis assessing the impact of pharmaceutical care for people with diabetes, in outpatient services, revealed a $1.1 \%$ reduction in HbA1c compared to standard care (95\% CI 0.88-1.27) [57]. In Brazil, a 12 months study enrolling patients with $\mathrm{DM}$, followed in a pharmacy, showed a reduction of $2.2 \%$ in HbA1c compared to $0.3 \%$ in the control group [58]. These studies suggest that the health care intervention by the pharmacist in patients with DM can improve the HbA1c results acting as an "additional" effect to the standard care provided to the patient. Other parameters such as blood pressure, LDL cholesterol, triglycerides, BMI, and coronary risk were also sensitive to pharmaceutical intervention in this group of patients, as reported by Pousinho et al. [59].

Barcelo et al. [60] found that most of the direct costs of treating DM in Latin America are related to the treatment of complications. Additionally,the cost of a patient without chronic complications with $\mathrm{HbA1c}>10 \%$ is 2.4 times higher when compared to a better controlled patient, with $\mathrm{HbA} 1 \mathrm{c}<8 \%$. If the patient develops chronic complications, the resultant cost is 34 times higher [61]. Therefore, population-based DM screening actions can generate cost-effective results [62].

The campaign to track suspected cases of DM in Brazil, in 2018, reached a population larger than the number initially estimated, reinforcing the role of pharmacies in health promotion and disease prevention activities. As in other countries [51, 52], pharmacies in Brazil are health establishments that provide pharmaceutical services, individual and collective health guidance, handling and/or dispensing medications, and evaluation of CBG, blood pressure and weight measurements, among other procedures [24, 25]. Thus, pharmacies are favorable environments for carrying out clinical activities, including screening, education, and monitoring of people with NCD, particularly diabetes [63].

\section{Strengths and limitations}

This is the first Brazilian T2DM screening study in pharmacies, using CBG test. The sample screened in this study was higher than expected; thus, the approach presented herein reinforces the strategic importance of the health services provided by community pharmacies for screening actions across the country. Another strength of the study was the opportunity to expand the application of the FINDRISC tool, which has been already translated and validated for the Brazilian Portuguese and is strongly recommended by the Brazilian Diabetes Society in its yearly detection campaigns. The completion of the questionnaire by health professionals, as performed herein, is expected to have increased the reliability of the data [14].

This study has some limitations. Because it is a crosssectional study, a causal relationship cannot be established. Another possible limitation was the population screened since it was a convenience sample and most participants had 11 or more years of formal education plus the fact that the majority of the pharmacies were private. Therefore, it is possible that the more vulnerable and least assisted people and also frequently less educated were under evaluated. In Brazil, 20.6\% of the inhabitants have an educational level of less than 3 years of formal education [64] and only $5.6 \%$ of the evaluated sample had this characteristic. Thus, although the frequency reported herein is alarming, it may be underestimated.

\section{Conclusions}

This is the largest study ever conducted in Brazil to assess the frequency of high blood glucose levels and the risk for the development of T2DM, performed by pharmacists,. The profile of the people who were found to have high CBG indicates that strategies involving health education measures, encouragement to healthy eating, physical activity and weight loss could help to reduce the prevalence of T2DM in the country, especially in the most underserved regions of the country, North, Northeast and Midwest where the increase in obesity is an important concern. Therefore, pharmacists working in community pharmacies may contribute to screening of NCD, such as T2DM, and perform health education, in the early referral of suspected cases to the health service for diagnostic confirmation, as well as in the monitoring of the patient with DM, in collaboration with the other health professionals and produce better results in the disease control.

Public health actions directed to the population with high CBG can enable the early diagnosis of T2DM, and contributes to the reduction of ASCVD, prevention of microvascular complications and avoid premature mortality. Worth to quote the partnership between the 
Brazilian Diabetes Society and the Federal Council of Pharmacists which represents an important step towards the liaison of pharmacists and other HCP involved in screening and care of people with diabetes in Brazil.

\begin{abstract}
Abbreviations
ASCVD: Atherosclerotic Cardiovascular Diseases; BMI: Body Mass Index; CBG: Capilar Blood Glucose; Cl: Confidence Interval; DM: Diabetes Mellitus; FINDRISC: Finnish Diabetes Risk Score; HCP: Health Care Professional; NCD: NonCommunicable Disease; PR: Prevalence ratio;T1DM:Type 1 Diabetes Mellitus; T2DM: Type 2 Diabetes Mellitus.
\end{abstract}

\section{Acknowledgements}

The authors acknowledge the support from pharmacists, the Brazilian Federal Council of Pharmacy and the Brazilian Diabetes Society during the activities of the Blue Diabetes November campaign.

\section{Authors' contributions}

Conception and study design: CJC, WCV, KFSM, JCQPF, JVA, MSAL, EBP, JSR, JP, HCP, WSJJ. Analysis and interpretation of data: CJC, WCV, JCQPF, LGN, RCRMN, MSAL, EBP, WMF. Drafting of the manuscript; CJS; WCV; RCRMN; JCQPF; LGN; WMF; HCP; WSJJ. All authors read and approved the final manuscript.

\section{Funding}

There was no funding for this study.

\section{Availability of data and materials}

The datasets used during the current study are available from the corresponding author on reasonable request.

\section{Ethics approval and consent to participate}

The research was approved by the Research Ethics Committees of the Federal University of Parana and the Federal University of Ouro Preto under number 95218118.4.0000.0102 / 2018. All interviews were conducted by the pharmacists preceded by clarifying the objectives for the participant and signing the informed consent form.

\section{Consent for publication}

A written consent to publish the information and data of the participants was obtained.

\section{Competing interests}

There are no competing interests to declare.

\begin{abstract}
Author details
${ }^{1}$ Departamento de Farmácia, Universidade Federal do Paraná, Curitiba, Paraná, Brazil. ${ }^{2}$ Programa de Pós Graduação em Ciências Farmacêuticas, Escola de Farmácia, Universidade Federal de Ouro Preto, Ouro Preto, Minas Gerais, Brazil. ${ }^{3}$ Conselho Federal de Farmácia, Brasília, Distrito Federal, Brazil. ${ }^{4}$ Sociedade Brasileira de Diabetes, Ensino e Pesquisa da Santa Casa de Belo Horizonte, Belo Horizonte, Minas Gerais, Brazil. ${ }^{5}$ Sociedade Brasileira de Diabetes, Equipe de Diabetes do Hospital das Clínicas da Faculdade de Medicina da Universidade de São Paulo, São Paulo, Brazil. ${ }^{6}$ Sociedade Brasileira de Diabetes, São Paulo, Brazil. ${ }^{7}$ Secretaria de Estado da Saúde, Polo de Pesquisa da Unidade de Endocrinologia FEPECS-HRT, Brasília, Distrito Federal, Brazil.
\end{abstract}

Received: 11 August 2020 Accepted: 23 September 2020

Published online: 08 October 2020

\section{References}

1. Lozano R, Naghavi M, Foreman K, Lim S, Shibuya K, Aboyans V, et al. Global and regional mortality from 235 causes of death for 20 age groups in 1990 and 2010: a systematic analysis for the Global Burden of Disease Study 2010. Lancet. 2012;380:2095-128.
2. Arredondo A, Aviles R. Costs and epidemiological changes of chronic diseases: implications and challenges for health systems. PLOS ONE. 2015;10:e0118611.

3. International Diabetes Federation. IDF Diabetes Atlas Ninth edition. 2019. https://www.diabetesatlas.org/en/. Accessed 16 Jun 2020.

4. Shaw JE, Sicree RA, Zimmet PZ. Global estimates of the prevalence of diabetes for 2010 and 2030. Diabetes Res Clin Pract. 2010;87:4-14.

5. Brasil. VIGITEL Brasil 2017 Vigilância de fatores de risco e proteção para doenças crônicas por inquérito telefônico. 2017. https://bvsms.saude .gov.br/bvs/publicacoes/vigitel_brasil_2017_vigilancia_fatores_risco s.pdf. Accessed 08 Apr 2018.

6. Malta DC, Duncan BB, Schmidt MI, Machado IE, Silva AG, Bernal RTI, et al. Prevalence of diabetes mellitus as determined by glycated hemoglobin in the Brazilian adult population National Health Survey. Rev Bras Epidemiol. 2019;22:E190006.

7. Schmidt MI, Hoffmann JF, de Fatima Sander Diniz M, Lotufo PA, Griep $\mathrm{RH}$, Bensenor IM, et al. High prevalence of diabetes and intermediate hyperglycemia - The Brazilian Longitudinal Study of Adult Health (ELSA-Brasil). Diabetol Metab Syndr. 2014;6:123.

8. Mendes AB, Fittipaldi JA, Neves RC, Chacra AR, Moreira ED Jr. Prevalence and correlates of inadequate glycaemic control: results from a nationwide survey in 6,671 adults with diabetes in Brazil. Acta Diabetol. 2010;47:137-45

9. Gomes MB, Coral M, Cobas RA, Dib SA, Canani LH, Nery M, et al. Prevalence of adults with type 1 diabetes who meet the goals of care in daily clinical practice: a nationwide multicenter study in Brazil. Diabetes Res Clin Pract. 2012;97:63-70.

10. Gomes MB, Gianella D, Faria M, Tambascia M, Fonseca RM, Rea R, et al. Prevalence of Type 2 diabetic patients within the targets of care guidelines in daily clinical practice: a multi-center study in Brazil. Rev Diabetic Stud. 2006:3:82-7.

11. Saraiva JFK, Hissa MN, Felício JS, Cavalcanti CAJ, Saraiva GL, Piha T, et al. Diabetes Mellitus in Brazil: clinical characteristics, standard treatment choice and cost. J Bras Econ Saúde. 2016;8:80-90.

12. Bahia LR, Araujo DV, Schaan BD, Dib SA, Negrato CA, Leao MP, et al. The costs of type 2 diabetes mellitus outpatient care in the Brazilian public health system. Value Health. 2011;14:S137-S140140.

13. Lindstrom J, Tuomilehto J. The diabetes risk score: a practical tool to predict type 2 diabetes risk. Diabetes Care. 2003;26:725-31.

14. Meijnikman AS, De Block CE, Verrijken A, Mertens I, Corthouts B, Van Gaal LF. Screening for type 2 diabetes mellitus in overweight and obese subjects made easy by the FINDRISC score. J Diabetes Complications. 2016;30:1043-9.

15. Meijnikman AS, De Block CEM, Verrijken A, Mertens I, Van Gaal LF. Predicting type 2 diabetes mellitus: a comparison between the FINDRISC score and the metabolic syndrome. Diabetol Metab Syndr. 2018;10:12.

16. Makrilakis K, Liatis S, Grammatikou S, Perrea D, Stathi C, Tsiligros P, et al. Validation of the Finnish diabetes risk score (FINDRISC) questionnaire for screening for undiagnosed type 2 diabetes, dysglycaemia and the metabolic syndrome in Greece. Diabetol Metab. 2011;37:144-51.

17. Stiglic G, Fijacko N, Stozer A, Sheikh A, Pajnkihar M. Validation of the Finnish Diabetes Risk Score (FINDRISC) questionnaire for undiagnosed type 2 diabetes screening in the Slovenian working population. Diabetes Res Clin Pract. 2016;120:194-7.

18. Sociedade Brasileira de Diabetes. Guidelines of the Brazilian Diabetes Society 2017-2018. https://www.diabetes.org.br/profissionais/image s/2017/diretrizes/diretrizes-sbd-2017-2018.pdf. Accessed 20 Sep 2019.

19. Krass I, Armour CL, Mitchell B, Brillant M, Dienaar R, Hughes J, et al. The Pharmacy Diabetes Care Program: assessment of a community pharmacy diabetes service model in Australia. Diabetic Med. 2007;24:677-83.

20. Fikri-Benbrahim N, Martinez-Martinez F, Saez-Benito L, Luque BS, Corpas JP, Moullin JC, The DiabNow Study, et al. Assessment of a screening protocol for type 2 diabetes in community pharmacy. Diabetes Res Clin Pract. 2015;108:e49-52.

21. Hersberger KE, Botomino A, Mancini M, Bruppacher R. Sequential screening for diabetes-evaluation of a campaign in Swiss community pharmacies. Pharm World Sci. 2006;28:171-9.

22. Papastergiou J, Folkins C, Li W. Community pharmacy-based A1C screening: a Canadian model for diabetes care. Int J Pharm Pract. 2016:24:189-95. 
23. Willis A, Rivers P, Gray $\sqcup$, Davies M, Khunti K. The effectiveness of screening for diabetes and cardiovascular disease risk factors in a community pharmacy setting. PLoS ONE. 2014;9:e91157.

24. Brazil. Law no. 13,021, of August 8, 2014. Provides for the exercise and inspection of pharmaceutical activities. Federal Official Gazette, Executive Branch, Brasília, DF, 11 Aug. 2014a. Section 1, p. 1, Extra Edition.https:// pesquisa.in.gov.br/imprensa/jsp/visualiza/index.jsp?jornal=1000\&pagin $a=1 \&$ data $=11 / 08 / 2014 \&$ totalArquivos=4. Accessed 17 Jan 2017

25. Agência Nacional de Vigilância Sanitária. RDC Resolution 44, of August 17, 2009. Provides for Good Pharmaceutical Practices for the sanitary control of the functioning, dispensing and commercialization of products and the provision of pharmaceutical services in pharmacies and drugstores and other measures. http://portal.anvisa.gov.br/documents/10181/27183 76/RDC_44_2009_COMP.pdf/2180ce5f-64bb-4062-a82f-4d9fa343c06e. Accessed 18 Jan 2018

26. IBGE. Projection of the Brazilian population. 2017. https://www.ibge.gov. br/apps/populacao/projecao/. Accessed 15 Jan 2017

27. International Diabetes Federation. IDF Diabetes Atlas Ninth edition. 2017. https://www.diabetes.org.br/profissionais/images/2018/poster-atlas-idf2017.pdf. Accessed 14 Jan 2018

28. World Health Organization. The legal and regulatory framework for community pharmacies in the WHO European Region. Geneva: World Health Oganization; 2019. p. 100.

29. Conselho Federal de Farmácia. November blue diabetes campaign. 2018. https://www.cff.org.br/pagina.php?id=826. Accessed 10 Jun 2020.

30. Conselho Federal de Farmácia. November blue diabetes campaign official website. 2018.https://www.diabetes.cff.org.br/. Accessed 10 Jun 2020.

31. Barim EM, McLellan KCP, Ribeiro RS, Carvalho JAM, Lindström J, Tuomilehto J, et al. Translation and cultural adaptation into Brazilian Portuguese of the Finnish Diabetes Risk Score (FINDRISC) and reliability assessment. Rev Bras Epidemiol. 2020. https://doi.org/10.1590/1980-549720200060.

32. ABESO. Associação Brasileira para o Estudo da Obesidade e da Síndrome Metabólica Diretrizes brasileiras de obesidade. 2016. https://abeso.org.br/ wp-content/uploads/2019/12/Diretrizes-Download-Diretrizes-Brasileira s-de-Obesidade-2016.pdf. Accessed 10 Jan 2018.

33. World Health Organization. Data Global status report on noncommunicable diseases 2014. Switzerland: WHO Library Cataloguing-in-Publication Data. 2014. https://apps.who.int/iris/bitstream/handle/10665/14811 4/9789241564854_eng.pdf;jsessionid=7164ABD7E36ECA51992A1C50F A8FCF6B? sequence=1. Acessed 16 Jun 2020.

34. Rhee EJ. Nonalcoholic fatty liver disease and diabetes: an epidemiological perspective. Endocrinol Metab. 2019;34:226-33.

35. Stefan N, Haring HU, Cusi K. Non-alcoholic fatty liver disease: causes, diagnosis, cardiometabolic consequences, and treatment strategies. Lancet Diabetes Endocrinol. 2019;7:313-24.

36. Dias PC, Henriques P, Anjos LA, Burlandy L. Obesity and public policies: the Brazilian government's definitions and strategies. Cad Saúde Pública. 2017;33:1-12

37. Brasil. VIGITEL Brasil 2018 Vigilância de fatores de risco e proteção para doenças crônicas por inquérito telefônico. 2018. https://portalarquivos2 .saude.gov.br/images/pdf/2019/julho/25/vigitel-brasil-2018.pdf. Accessed Apr 2019.

38. Cepas V, Collino M, Mayo JC, Sainz RM. Redox signaling and Advanced Glycation Endproducts (AGEs) in diet-related diseases. Antioxidants. 2020;9:142.

39. Nowotny K, Jung T, Hohn A, Weber D, Grune T. Advanced glycation end products and oxidative stress in type 2 diabetes mellitus. Biomolecules. 2015:5:194-222.

40. Kowluru RA, Kanwar M. Effects of curcumin on retinal oxidative stress and inflammation in diabetes. Nutr Metab. 2007:4:8

41. Kaul K, Hodgkinson A, Tarr JM, Kohner EM, Chibber R. Is inflammation a common retinal-renal-nerve pathogenic link in diabetes? Curr Diabetes Rev. 2010;6:294-303.

42. Herder C, Roden M, Ziegler D. Novel insights into sensorimotor and cardiovascular autonomic neuropathy from recent-onset diabetes and population-based cohorts. Trends Endocrinol Metab. 2019:30:286-98.

43. Kruit A, Zanen P. The association between vitamin D and C-reactive protein levels in patients with inflammatory and non-inflammatory diseases. Clin Biochem. 2016:49:534-7.

44. Pittas AG, Jorde R, Kawahara T, Dawson-Hughes B. Vitamin D supplementation for prevention of type 2 diabetes mellitus. To D or not to D? J Clin Endocrinol Metab. 2020. https://doi.org/10.1210/clinem/dgaa594.
45. Passos VM, Barreto SM, Diniz LM, Lima-Costa MF. Type 2 diabetes: prevalence and associated factors in a Brazilian community-the Bambui health and aging study. Sao Paulo Med J. 2005;123:66-71.

46. Mayer-Davis EJ, D'Agostino R Jr, Karter AJ, Haffner SM, Rewers MJ, Saad $M$, et al. Intensity and amount of physical activity in relation to insulin sensitivity: the Insulin Resistance Atherosclerosis Study. JAMA. 1998:279:669-74.

47. Alberti KG, Zimmet P, Shaw J. International Diabetes Federation: a consensus on type 2 diabetes prevention. Diabetic Med. 2007:24:451-63.

48. Kirpichnikov D, Sowers JR. Diabetes mellitus and diabetes-associated vascular disease. Trends Endocrinol Metab. 2001;12:225-30.

49. Sowers JR, Epstein M, Frohlich ED. Diabetes, hypertension, and cardiovascular disease: an update. Hypertension. 2001;37:1053-9.

50. Fornos-Perez JA, Andres-Rodriguez NF, Andres-Iglesias JC, Luna-Cano R, Garcia-Soidan J, Lorenzo-Veiga B, et al. Detection of people at risk of diabetes in community pharmacies of Pontevedra (Spain) (DEDIPO). Endocrinol Nutr. 2016;63:387-96.

51. Dhippayom T, Fuangchan A, Tunpichart S, Chaiyakunapruk N. Opportunistic screening and health promotion for type 2 diabetes: an expanding public health role for the community pharmacist. J Public Health. 2013;35:262-9

52. Bovet $P$, Hirsiger P, Emery F, De Bernardini J, Rossier C, Trebeljahr J, et al. Impact and cost of a 2-week community-based screening and awareness program for diabetes and cardiovascular risk factors in a Swiss canton. Diabetes Metab Syndr Obes. 2011;4:213-23.

53. Chaturvedi N. The burden of diabetes and its complications: trends and implications for intervention. Diabetes Res Clin Pract. 2007;76(Suppl 1):S3-12

54. Saaristo T, Peltonen M, Keinanen-Kiukaanniemi S, Vanhala M, Saltevo J, Niskanen L, et al. National type 2 diabetes prevention programme in Finland: FIN-D2D. Int J Circumpolar Health. 2007:66:101-12.

55. Grisold A, Callaghan BC, Feldman EL. Mediators of diabetic neuropathy: is hyperglycemia the only culprit? Curr Opin Endocrinol Diabetes Obes. 2017;24:103-11.

56. Sociedade Brasileira de Diabetes. Diretrizes Sociedade Brasileira de Diabetes 2019-2020. 2019. https://www.diabetes.org.br/profissionais/images/ DIRETRIZES-COMPLETA-2019-2020.pdf. Acessed Jun 2020.

57. Fazel MT, Bagalagel A, Lee JK, Martin JR, Slack MK. Impact of diabetes care by pharmacists as part of health care team in ambulatory settings: a systematic review and meta-analysis. Ann Pharmacother. 2017;51:890-907.

58. Correr CJ, Melchiors AC, Fernandez-Llimos F, Pontarolo R. Effects of a pharmacotherapy follow-up in community pharmacies on type 2 diabetes patients in Brazil. Int J Clin Pharm. 2011;33:273-80.

59. Pousinho S, Morgado M, Falcao A, Alves G. Pharmacist interventions in the management of type 2 diabetes mellitus: a systematic review of randomized controlled trials. JMCP. 2016;22:493-515.

60. Barcelo A, Arredondo A, Gordillo-Tobar A, Segovia J, Qiang A. The cost of diabetes in Latin America and the Caribbean in 2015: Evidence for decision and policy makers. J Glob Health. 2017;7:020410.

61. Menzin J, Langley-Hawthorne C, Friedman M, Boulanger L, Cavanaugh R. Potential short-term economic benefits of improved glycemic control: a managed care perspective. Diabetes Care. 2001;24:51-5.

62. Georg AE, Duncan BB, Toscano CM, Schmidt MI, Mengue S, Duarte C, et al. Economic analysis of a screening program for diabetes mellitus in Brazil. Rev Saúde Pública. 2005:39:452-60.

63. Conselho Federal de Farmácia. Resolution No. 585, of August 29, 2013. Published in the Official Gazette, Page 186 of Section 1 of the Official Gazette (DOU) of September 25, 2013. https://pesquisa.in.gov.br/ imprensa/jsp/visualiza/index.jsp?data $=25 / 09 / 2013 \&$ jornal=1\&pagin $a=186 \&$ totalArquivos=192. Accessed 19 Apr 2018

64. IBGE. Brazil in summary, education, years of study. https://brasilemsintese ibge.gov.br/educacao/anos-de-estudo.html. Accessed 01 Sep 2020.

\section{Publisher's Note}

Springer Nature remains neutral with regard to jurisdictional claims in published maps and institutional affiliations. 